\title{
STRATEGI PENGEMBANGAN PELABUHAN PERIKANAN NIZAM ZACHMAN DALAM MENDUKUNG INDUSTRI PERIKANAN TUNA
}

\section{NIZAM ZACHMAN FISHING PORT DEVELOPMENT STRATEGY IN SUPPORTING TUNA FISHERIES INDUSTRY}

\section{Roma Yuli Felina Hutapea ${ }^{1}$, Iin Solihin ${ }^{2}$, Tri Wiji Nurani ${ }^{2}$, Ayang Armelita Rosalia ${ }^{3}$, Aprilia Syah Putri ${ }^{4}$}

${ }^{1}$ Program Studi Perikanan Tangkap, Politeknik Kelautan dan Perikanan Dumai, Kementerian Kelautan dan Perikanan ${ }^{2}$ Departemen Pemanfaatan Sumberdaya Perikanan, Fakultas Perikanan dan Ilmu Kelautan, Institut Pertanian Bogor

${ }^{3}$ Program Studi Sistem Informasi Kelautan, Universitas Pendidikan Indonesia

${ }^{4}$ Program Studi Perikanan Tangkap, Jurusan Peternakan, Politeknik Negeri Lampung

Korespondensi: romafelina@yahoo.co.id; romahutapea3@gmail.com

\begin{abstract}
The role of fishing ports required in tuna fishing industries. Oceanic Fishing Port Nizam Zachman is a tuna fishing port in Indonesia, which includes the tuna fishing industrty. The increasing role of Nizam Zachman Oceanic Fishing Port is needed by tuna stakeholders to optimize the performance and services provided by the port. The aimed of the research was to formulate the development strategy of tuna industries, which is competitive with used the role of Nizam Zachman Oceanic Fishing Port. The analysis methods that used in this research was SWOT analysis by comparing the internal factors and external factors tuna fisheries development. The results showed that there were 6 tuna fisheries development strategy by optimizing the role of Nizam Zachman Oceanic Fishing Port.
\end{abstract}

Keywords: development, Nizam Zachman, strategy, tuna fishing industries

\begin{abstract}
ABSTRAK
Peran dari pelabuhan perikanan diperlukan dalam industri perikanan tuna yang didaratkan di pelabuhan perikanan. Pelabuhan Perikanan Samudera (PPS) Nizam Zachman merupakan pelabuhan perikanan tuna di Indonesia, yang didalamnya terdapat industri perikanan tuna. Peningkatan peran dari PPS Nizam Zachman diperlukan oleh stakeholder tuna untuk mengoptimalkan kinerja serta pelayanan yang diberikan oleh pelabuhan. Tujuan dari penelitian ini yaitu merumuskan strategi pengembangan industri tuna PPS Nizam Zachman. Metode penelitian dilakukan dengan analisis SWOT dengan membandingkan faktor internal dan faktor eksternal pengembangan industri perikanan tuna. Hasil penelitian menunjukkan bahwa terdapat 6 strategi pengembangan industri perikanan tuna dengan mengoptimasikan peran dari PPS Nizam Zachman.
\end{abstract}

Kata kunci: industri perikanan tuna, Nizam Zachman, pengembangan, strategi 


\section{PENDAHULUAN}

PPS Nizam Zachman sebagai pelabuhan perikanan terbesar tipe samudera yang ada di Indonesia diharapkan mampu memberikan dampak yang dapat dirasakan kinerjanya oleh seluruh pengguna pelabuhan, salah satunya stakeholder tuna. Baik dari fasilitas yang disediakan, sumber daya manusia yang kompeten, pelayanan yang disediakan, dan lain-lain. Berdasarkan penelitian pendahuluan mengenai fungsi dan peran dari PPS Nizam Zachman terhadap industri perikanan tuna yang berada di dalam PPS, didapatkan hasil pelabuhan perikanan berperan baik dalam mendukung industri tuna.

Fungsi dan peran pelabuhan terhadap industri yang berada di dalam lingkungan PPS yaitu aktivitas produksi, sarana dan prasarana, pendaratan, pemasaran, distribusi hasil tangkapan serta pelayanan umum mulai dari perijinan, penyediaan kebutuhan es, penyediaan BBM, pelayanan pengolahan hasil perikanan, pelayaran jasa tambat labuh, bongkar muat, kemudahan akses dan transportasi menuju lokasi pelabuhan. Namun, stakeholder tuna masih merasa belum puas terhadap beberapa pelayanan atau jasa yang disediakan oleh pihak pelabuhan. Diharapkan PPS Nizam Zachman dapat lebih memperhatikan dan memperbaiki pelayanan-pelayanan yang dinilai oleh responden masih kurang.

Peran dari pelabuhan perikanan tidak hanya dalam menjamin keberhasilan usaha perikanan tangkap, sebagai pusat perekonomian dan kegiatan perikanan, yaitu seperti penyediaan berbagai fasilitas dan pelayanan yang dapat diakses oleh seluruh pengguna pelabuhan (KKP 2012). Namun pada kenyataannya, masih terjadi gap antara kinerja dari pelabuhan, yang selama ini dijalankan oleh pihak pelabuhan terhadap ekspektasi atau harapan dari stakeholder (Hutapea et al. 2017). Ketidakpuasan stakeholder inilah yang mengakibatkan penilaian dari stakeholder, terhadap kinerja yang telah dijalankan oleh PPS Nizam Zachman menjadi rendah.

Dukungan dari pelabuhan perikanan yang belum optimal menimbulkan berbagai masalah di industri perikanan tuna. Salah satu permasalahannya adalah penolakan ekspor tuna ke luar negeri. Penolakan ini disebabkan oleh penanganan ikan tuna yang kurang baik, mulai dari aktivitas penangkapan, proses, hingga tingginya kandungan bakteri atau kadar histamin yang tinggi (Nurani et al. 2013). Masalah lainnya adalah belum terpenuhinya kebutuhan stakeholder dalam hal pengurusan surat perizinan, tambat labuh, docking kapal, serta jalan di kawasan berdampak bagi operasional di industri perikanan (Harefa et al. 2019), sehingga diperlukan berbagai strategi yang dapat digunakan untuk meningkatkan peran PPS Nizam Zachman, khususnya dalam mendukung industri perikanan tuna.

Strategi menurut Rangkuti (2006) dianalisis berdasarkan pemahaman mengenai situasi dan informasi yang ada; pemahaman mengenai masalah yang terjadi, baik yang bersifat umum maupun spesifik; menciptakan berbagai alternatif dan memberikan berbagai alternatif pemecahan masalah; serta mengevaluasi pilihan alternatif dan pilihan alternatif yang terbaik.

Penilaian peran dan kinerja dari PPS Nizam Zachman khususnya dalam mendukung industri perikanan tuna dapat dijadikan bahan masukan dalam perumusan strategi pengembangan pelabuhan. Selain itu, perlu diidentifikasi faktor-faktor lain yang berpengaruh terhadap pengembangan PPS Nizam Zachman. Tujuan dari penelitian ini adalah untuk merumuskan strategi pengembangan PPS Nizam Zachman dalam mendukung industri perikanan tuna dan diharapkan memberikan manfaat bagi pengelola pelabuhan sebagai bahan pertimbangan dalam penyusunan strategi pengembangan pelabuhan. Fokus penelitian ini pada industri pengolahan tuna dan industri tuna segar di PPS Nizam Zachman.

\section{METODE PENELITIAN}

\section{Waktu dan tempat}

Penelitian dilaksanakan pada bulan Maret hingga September 2016, bertempat di industri tuna kawasan PPS Nizam Zachman Jakarta. Dilanjutkan dengan studi literatur dan studi kasus pada bulan Maret hingga April 2020.

\section{Pengumpulan data}

Metode penelitian yang digunakan dalam penentuan strategi pengembangan PPS Nizam Zachman adalah metode survei. Data dikumpulkan melalui pengamatan 
langsung di pelabuhan, studi kasus dan wawancara. Responden yang diwawancarai sebanyak 9 orang dilakukan secara purposive berdasarkan kesediaan stakeholder untuk dijadikan responden. Responden tersebut meliputi 7 orang dari manajemen di industri pengolahan tuna, serta 2 orang dari pengelola pelabuhan.

\section{Analisis data}

Penyusunan strategi pengembangan PPS Nizam Zachman dalam mendukung industri perikanan tuna menggunakan analisis SWOT (Strenght, Weakness, Opportunities, Treaths). Analisis SWOT membandingkan antara faktor internal (kekuatan dan kelemahan) dengan faktor eksternal (peluang dan ancaman). Sebelum merumuskan strategi, terlebih dahulu kita analisa kasus yang didalamnya menjelaskan situasi dan informasi yang ada, terkait dengan objek yang kita teliti. Tahapan dalam analisis kasus adalah sebagai berikut:

Tahap 1 : Pemahaman mengenai situasi dan informasi yang ada (pemahaman mengenai peran dari PPS Nizam Zachman dalam mendukung industri tuna);

Tahap 2 : Pemahaman mengenai permasalahan yang terjadi. Baik masalah yang bersifat umum maupun spesifik;

Tahap 3 : Menciptakan berbagai alternatif dan memberikan berbagai alternatif pemecahan masalah;

Tahap 4 : Evaluasi pilihan alternatif dan memilih alternatif yang terbaik.

Menurut Rangkuti (2006), proses perumusan strategi melalui 3 tahap analisis yaitu:
1. Tahap pengumpulan data

Tahap pengumpulan data tidak hanya sekedar kegiatan pengumpulan data, tetapi merupakan kegiatan pengklasifikasian dan pra-analisis.

2. Tahap analisis

Tahap analisis dibedakan menjadi dua, yaitu data internal (kekuatan dan kelemahan) dan data eksternal (peluang dan ancaman) PPS Nizam Zachman. Model yang dipakai pada tahap ini adalah matriks SWOT. Matriks SWOT terdapat pada Tabel 1.

Menurut Rangkuti (2006), dengan posisi perusahaan pada kuadran yang tepat maka perusahaan dapat mengambil keputusan dengan lebih tepat, yaitu:

1. Jika posisi perusahaan berada pada kuadran I maka strategi yang harus diterapkan untuk perusahaan yang berada pada posisi ini adalah mendukung kebijakan pertumbuhan yang agresif. Posisi pada kuadran I merupakan situasi yang sangat menguntungkan. Perusahaan memiliki peluang dan kekuatan sehingga dapat memanfaatkan peluang yang ada.

2. Jika posisi perusahaan berada pada kuadran II maka strategi yang harus dilakukan adalah menggunakan kekuatan untuk memanfaatkan peluang jangka panjang dengan cara strategi diversifikasi (produk/jasa).

3. Jika posisi perusahaan berada pada kuadran III menunjukkan bahwa perusahaan mempunyai peluang yang sangat besar, tetapi dilain pihak perusahaan memiliki kelemahan internal.

Tabel 1. Matriks SWOT

\begin{tabular}{|c|c|c|}
\hline EFAS & $\begin{array}{l}\text { Strength }(\mathrm{S}) \\
\text { Tentukan faktor-faktor } \\
\text { kekuatan internal }\end{array}$ & $\begin{array}{l}\quad \text { Weaknesses }(\mathrm{W}) \\
\text { Tentukan faktor-faktor } \\
\text { kelemahan internal }\end{array}$ \\
\hline \begin{tabular}{l}
\multicolumn{1}{c}{ Opportunies $(\mathrm{O})$} \\
Tentukan faktor-faktor \\
peluang eksternal
\end{tabular} & \begin{tabular}{l} 
Strategi SO \\
Ciptakan strategi yang \\
menggunakan kekuatan \\
untuk memanfaatkan pelu- \\
ang. \\
\multicolumn{2}{c}{ Kuadran I } \\
\end{tabular} & \begin{tabular}{l}
\multicolumn{1}{c}{ Strategi WO } \\
Ciptakan strategi yang \\
meminimalkan kelema- \\
han untuk memanfaatkan \\
peluang \\
$\quad$ Kuadran III \\
\end{tabular} \\
\hline $\begin{array}{l}\quad \text { Treaths }(\mathrm{T}) \\
\text { Tentukan faktor-faktor } \\
\text { peluang eksternal }\end{array}$ & $\begin{array}{l}\text { Strategi ST } \\
\text { Ciptakan strategi yang } \\
\text { menggunakan kekuatan } \\
\text { untuk mengatasi ancaman } \\
\text { Kuadran II } \\
\end{array}$ & \begin{tabular}{l}
\multicolumn{1}{c}{ Strategi WT } \\
Ciptakan strategi yang \\
meminimalkan kelemahan \\
dan menghindari ancaman \\
Kuadran IV \\
\end{tabular} \\
\hline
\end{tabular}


4. Jika posisi perusahaan berada pada kuadran IV menunjukkan dimana perusahaan menghadapi berbagai ancaman, juga menghadapi kelemahan internal.

3. Tahap pengambilan keputusan

Menentukan kombinasi strategi pengembangan industri perikanan tuna berdaya saing yang tepat dengan mempertimbangkan faktor-faktor internal dan eksternal industri perikanan tuna.

4. Tahapan penentuan prioritas strategi

Penentuan prioritas strategi dilakukan dengan menggunakan metode USG (Urgency, Seriousness, Growth). Metode USG merupakan salah satu metode analisis sosial secara kualitatif yang biasa digunakan dalam menentukan pentingnya suatu masalah dibandingkan dengan masalah lainnya (Utari dan Wahyuni 2020), namun pada tahapan ini peneliti memodifikasi/mengubah target yaitu prioritas masalah menjadi prioritas strategi. Metode USG ini dilakukan dengan metode skoring dengan mempertimbangkan tiga komponen USG.

Penjelasan dari ketiga komponen metode USG adalah sebagai berikut:

1. Urgency

Seberapa mendesak waktu yang dibutuhkan untuk menerapkan suatu stratego. Semakin mendesak suatu strategi untuk diterapkan maka semakin tinggi urgensi dari strategi tersebut.

2. Seriousness

Seberapa serius akibat/dampak yang ditimbulkan bila strategi tersebut tidak diterapkan dalam pengembangan pelabuhan. Semakin tinggi dampak strategi dalam pengembangan suatu pelabuhan, maka semakin serius/ penting strategi tersebut.

3. Growth

Seberapa mungkin strategi tersebut dapat dikembangkan oleh PPS Nizam Zachman, dalam mendukung industri tuna.

Pembobotan pada ketiga komponen metode USG dalam penentuan prioritas strategi pengembangan di PPS Nizam Zachman adalah sebagai berikut:

5 : sangat besar

4 : besar

3 : sedang

2 : kecil

1 : sangat kecil

\section{HASIL DAN PEMBAHASAN}

Peran PPS Nizam Zachman dalam mendukung industri tuna dinilai baik oleh responden, namun masih terdapat beberapa kinerja dari pelabuhan yang harus ditingkatkan khususnya dalam aktivitas produksi, sarana prasarana, dan pelayanan umum. Hasil penelitian menyebutkan bahwa masalah yang masih terjadi di PPS Nizam Zachman terkait peran pelabuhan dalam mendukung industri tuna adalah sebagai berikut:

1. Peran pelabuhan dalam menunjang ketersediaan bahan baku tuna;

2. Peran pelabuhan dalam menjaga sanitasi dan higienitas di pelabuhan dan di industri tuna;

3. Peran pelabuhan dalam penyediaan fasilitas pemasaran dan distribusi hasil perikanan (ke pasar, industri, kendaraan berpendingin);

4. Peran pelabuhan dalam pelayanan informasi harga dan pasar;

5. Peran pelabuhan dalam penyediaan fasilitas fungsional; dan

6. Peran pelabuhan dalam mengatasi masalah perizinan

Dari keenam permasalahan yang masih terjadi di PPS Nizam Zachman ini, kemudian dilakukan pemecahan masalah yaitu dengan melakukan analisis SWOT untuk mendapatkan strategi pengembangan PPS Nizam Zachman dalam mendukung industri perikanan tuna. Lubis dan Pane (2012) menyatakan bahwa peran strategis dari pelabuhan perikanan mendorong keberadaan industri perikanan di pelabuhan perikanan, tidak hanya skala lokal, namun regional bahkan internasional.

Perumusan strategi pengembangan PPS Nizam Zachman dalam mendukung industri tuna menggunakan analisis SWOT. Analisis SWOT merupakan metode perencanaan strategis berdasarkan analisis kekuatan, kelemahan, peluang, dan ancaman. Analisis SWOT menghasilkan strategi-strategi yang bertujuan agar PPS Nizam Zachman dapat lebih berkembang dan dapat memberikan pelayanan yang terbaik tidak hanya untuk industri tuna, tetapi seluruh pengguna pelabuhan. Berkembangnya PPS Nizam Zachman didukung dengan kinerja dari pelabuhan serta ketersediaan fasilitas di pelabuhan. Faktor internal dan eksternal PPS Nizam Zachman didapatkan berdasarkan identifikasi kondisi PPS Nizam Zachman 
dalam mendukung industri perikanan tuna. Faktor internal (kekuatan dan kelemahan) dan faktor eksternal (peluang dan ancaman) PPS Nizam Zachman terdapat pada Tabel 2. Penjelasan mengenai faktor-faktor internal (kekuatan dan kelemahan) dan faktor eksternal (peluang dan ancaman) industri tuna berdaya saing adalah sebagai berikut:

\section{Kekuatan (strengths)}

1. Tuna yang didaratkan memiliki nilai jual ekspor yang tinggi

Setiap produk ekspor tuna segar dan olahan yang yang berasal dari PPS Nizam Zachman memiliki nilai jual yang tinggi. Tingginya harga jual tuna yang ditawarkan oleh negara penerima ini sangat diapresiasi oleh stakeholder tuna Indonesia, sehingga stakeholder tuna merasa tidak dirugikan oleh harga yang dipatok oleh pasar asing. Berdasarkan wawancara dengan responden, harga beli tuna yang didaratkan di PPS Nizam Zachman berkisar antara Rp 40.000,00 hingga Rp 60.000,00 per kg, sedangkan harga jualnya bisa mencapai Rp 100.000,00 hingga Rp 200.000,00 per $\mathrm{kg}$.

2. Tersedianya SDM yang mampu menjalankan kegiatan di PPS Nizam Zachman berkaitan dengan penanganan tuna

PPS Nizam Zachman memiliki sumberdaya manusia (SDM) pengelola pelabuhan sebanyak 265 orang; yang terdiri dari pejabat struktural sebanyak 10 orang, pejabat fungsional sebanyak 7 orang, dan staf sebanyak 248 orang (DJPT 2015). SDM PPS Nizam Zachman menjalankan tugas dan kewajibannya berdasarkan jabatan/tugas. SDM yang bertugas dalam penanganan/ pemantauan ikan tuna yang didaratkan di PPS Nizam Zachman, biasanya telah memiliki basic pendidikan atau pelatihan yang diadakan oleh PPS Nizam Zachman.

3. Ketersediaan sarana prasarana pendukung industri perikanan tuna (air bersih, es, coldstorage)

Ketersediaan sarana prasarana di PPS Nizam Zachman yang mendukung industri tuna seperti air bersih, es, dan coldstorage sangat dibutuhkan stakeholder tuna untuk menunjang kegiatan produksi tuna. Kapasitas daya tampung air bersih di PPS Nizam Zachman adalah sebesar $4.600 \mathrm{~m}^{3}$ per hari. Suplai air bersih berasal dari PT.
Centra Niaga Eropindo, TSA, Palyja, dan Sea Water Reverse Osmosis. Coldstorage yang biasa digunakan oleh stakeholder tuna di PPS Nizam Zachman berjumlah 53 unit dengan kapasitas 1.000-3.000 ton dan gudang es di PPS Nizam Zachman mampu untuk menunjang kebutuhan industri tuna dan perbekalan armada penangkapan ikan dengan kapasitas gudang es sebanyak 216 ton hari.

4. Baiknya kualitas ikan tuna yang didaratkan di PPS Nizam Zachman

Baiknya kualitas ikan yang didaratkan di PPS Nizam Zachman menandakan bahwa penangkapan dan penanganan tuna di atas kapal telah baik, kesadaran nelayan untuk menangkap ikan dan melakukan penanganan ikan sangat berpengaruh terhadap grade/ nilai dari ikan tuna tersebut. Ikan tuna yang didaratkan nelayan di PPS Nizam Zachman mayoritas untuk skala ekspor.

Semakin baiknya kualitas dari hasil tangkapan yang didaratkan, akan berpengaruh terhadap nilai/harga jual dari produk tersebut. Penyeleksian kualitas/grade ikan dilakukan oleh checker untuk menentukan kualitas dari ikan tuna. Penyeleksian ini dilakukan dengan menggunakan alat coring tube yaitu alat yang berbentuk batang tajam dan terbuat dari besi. Kualitas mutu ikan tuna di PPS Nizam Zachman dibedakan menjadi empat kategori grade, yaitu grade A, B, C, dan D. Ikan yang memenuhi kualitas ekspor segar (grade A) dilakukan treatment (seperti pembersihan sisa isi perut dan insang, pencucian, penandaan, dan lainlain). Ikan yang tidak masuk kualitas eksport (grade $\mathrm{B}, \mathrm{C}$, dan D) akan dibawa ke perusahaan untuk dilakukan pengolahan.

5. Baiknya pendataan hasil tangkapan ikan yang didaratkan di PPS Nizam Zachman

Pendataan hasil tangkapan yang didaratkan di PPS Nizam Zachman dilakukan oleh enumerator PPS Nizam Zachman. Setelah pendataan hasil tangkapan, selanjutnya data akan dimasukkan ke dalam statistik perikanan PPS Nizam Zachman. Kelengkapan dan keakuratan pencatatan data sangat bermanfaat untuk pengambilan atau penentuan strategi keputusan berkaitan dengan stok/kondisi perikanan tangkap di PPS Nizam Zachman. 
Tabel 2. Faktor internal dan faktor eksternal PPS Nizam Zachman

\begin{tabular}{|c|c|c|c|}
\hline \multicolumn{3}{|c|}{ Kekuatan (Strengths) } & Kelemahan (Weakness) \\
\hline 1 & $\begin{array}{l}\text { Tuna yang didaratkan memiliki nilai jual } \\
\text { ekspor yang tinggi }\end{array}$ & 1 & $\begin{array}{l}\text { Keterbatasan dalam pemenuhan bahan } \\
\text { baku tuna }\end{array}$ \\
\hline 2 & $\begin{array}{l}\text { Tersedianya SDM yang mampu } \\
\text { menjalankan kegiatan di PPS Nizam } \\
\text { Zachman berkaitan dengan penanganan } \\
\text { tuna }\end{array}$ & 2 & $\begin{array}{l}\text { Penanganan tuna masih kurang higienis } \\
\text { saat didaratkan }\end{array}$ \\
\hline 3 & $\begin{array}{l}\text { Ketersediaan sarana prasarana } \\
\text { pendukung industri perikanan tuna (air } \\
\text { bersih, es, coldstorage) }\end{array}$ & 3 & $\begin{array}{l}\text { Minimnya ketersediaan fasilitas } \\
\text { pemasaran (ke industri, pasar) }\end{array}$ \\
\hline 4 & $\begin{array}{l}\text { Baiknya kualitas ikan tuna yang } \\
\text { didaratkan di PPS Nizam Zachman }\end{array}$ & 4 & $\begin{array}{l}\text { Minimnya pelayanan informasi harga } \\
\text { dan pasar }\end{array}$ \\
\hline 5 & $\begin{array}{l}\text { Baiknya pendataan hasil tangkapan ikan } \\
\text { yang didaratkan di PPS Nizam Zachman }\end{array}$ & 5 & $\begin{array}{l}\text { Minimnya } \\
\text { fungsional }\end{array}$ \\
\hline & Peluang (Opportunities) & & Ancaman (Threats) \\
\hline 1 & $\begin{array}{l}\text { Terbukanya peluang investor/pemberi } \\
\text { modal di PPS Nizam Zachman }\end{array}$ & 1 & $\begin{array}{l}\text { Penolakan produk perikanan tuna dari } \\
\text { luar negeri }\end{array}$ \\
\hline 2 & $\begin{array}{l}\text { Regulasi/kebijakan pemerintah terkait } \\
\text { industri tuna }\end{array}$ & 2 & $\begin{array}{l}\text { Persaingan harga tuna segar dan olahan } \\
\text { dari negara lain (kompetitor) }\end{array}$ \\
\hline 3 & $\begin{array}{l}\text { Aksesibilitas dari PPS Nizam Zachman } \\
\text { ke sarana transportasi pemasaran } \\
\text { (pelabuhan dan bandara) relatif mudah } \\
\text { dan cepat }\end{array}$ & 3 & $\begin{array}{l}\text { Standar mutu yang tinggi dari negara } \\
\text { lain }\end{array}$ \\
\hline 4 & Potensi permintaan tuna dunia & & \\
\hline
\end{tabular}

\section{Kelemahan (weakness)}

1. Keterbatasan dalam pemenuhan bahan baku tuna

Terbatasnya bahan baku yang didaratkan dirasakan oleh pengusaha tuna. Hasil tangkapan tuna yang didaratkan di dermaga transit dengan grade A - B dijual langsung untuk pasar Jepang dalam kondisi segar, sedangkan ikan tuna dengan grade dibawah B dijual kepada perusahaan yang membutuhkan bahan baku tuna, dengan harga yang telah disepakati. Solusi yang dilakukan pengusaha tuna mengatasi terbatasnya bahan baku tuna adalah mendatangkan bahan baku tuna dari luar PPS Nizam Zachman bahkan mendatangkan bahan baku tuna dari luar Indonesia, telah dilakukan oleh pengusaha tuna beberapa tahun terakhir ini. Penelitian sebelumnya menjelaskan bahwa saat ini stakeholder pengolahan tuna mengalami kekurangan bahan baku sebesar $\pm 15.053,92 \mathrm{~kg} /$ bulan. Permasalahan mengenai keterbatasan bahan baku harus dapat segera diselesaikan, agar stakeholder pengolahan tuna dapat tetap menjalankan kegiatan produksi pengolahan tuna.
2. Penanganan tuna masih kurang higienis saat didaratkan

Penanganan tuna di darat yang dinilai masih kurang higienis, dapat dilihat dari penggunaan papan seluncur yang digunakan untuk memindahkan ikan tuna dari atas kapal ke transit sheed masih terkena sinar matahari, orang masih dapat berlalu lalang saat pembongkaran tuna berlangsung, bahkan masih terdapatnya mobil pengangkut bahan baku tuna yang tidak menggunakan atap dan berpendingin sehingga menyebabkan terkena sinar matahari langsung. Penanganan yang kurang higienis ini juga dapat berdampak pada menurunnya kualitas dari ikan tuna.

3. Minimnya ketersediaan fasilitas pemasaran (ke industri, pasar, penyediaan kendaraan berpendingin)

Minimnya ketersediaan fasilitas pemasaran menyebabkan stakeholder tuna menyediakan sendiri fasilitas pemasaran berupa kendaraan berpendingin. Kendaraan berpendingin ini dipergunakan untuk mengangkut/ memindahkan ikan tuna dari Tuna Landing Center (TLC) ke industri 
pengolahan. Berdasarkan wawancara dengan responden, pihak PPS Nizam Zachman memang telah menyediakan kendaraan berpendingin. Kendaraan berpendingin yang disediakan oleh pelabuhan sangat minim, hanya sebanyak 2 unit kendaraan berpendingin. Minimnya jumlah kendaraan berpendingin yang disediakan oleh pelabuhan, menyebabkan stakeholder menyediakan sendiri kendaraan pengangkut tuna dari Tuna Landing Center (TLC) ke industri pengolahan.

4. Minimnya pelayanan informasi harga dan pasar

Minimnya informasi harga

ikan dan pasar yang disediakan oleh PPS Nizam Zachman mengakibatkan stakeholder tuna mencari/memperoleh informasi mengenai harga dan pasar tuna sendiri. Informasi harga tuna dan pasar tuna sangat diperlukan oleh stakeholder tuna dalam pemenuhan bahan baku untuk produksi. Informasi harga ikan dan pasar yang terupdate diperlukan oleh stakeholder tuna dalam melakukan transaksi jual beli bahan baku tuna.

5. Minimnya ketersediaan fasilitas fungsional

Minimnya ketersediaan fasilitas fungsional terkait industri pengolahan tuna, seperti tempat penanganan tuna, tempat pengolahan hasil perikanan, tempat pengolahan limbah dan lain sebagainya. Transit sheed merupakan salah satu tempat penanganan tuna yang jumlahnya semakin berkurang. Dari 30 unit transit sheed, hanya 4 dermaga transit saja yang saat ini biasa digunakan untuk penanganan tuna. Adapun transit yang lainnya ada beberapa yang beralih fungsi menjadi bengkel, gudang penyimpanan, cold storage, dan lain sebagainya.

\section{Peluang (opportunities)}

1. Terbukanya peluang investor/pemberi modal di PPS Nizam Zachman

Terbukanya peluang investor atau pemberi modal di PPS Nizam Zachman merupakan salah satu peluang dalam pengembangan PPS Nizam Zachman dalam mendukung industri perikanan tuna, karena dengan adanya investor maka dapat meningkatkan pendapatan dari PPS Nizam Zachman. Investor dalam negeri di PPS Nizam Zachman saat ini adalah ASTUIN (Asosiasi Tuna
Indonesia), serta pengusaha yang mendirikan perusahaan di Muara Baru. Perlu dilakukan kerja sama dengan negara asing seperti Malaysia, Hongkong, Vietnam, dan lain-lain yang tertarik untuk melakukan investasi di industri perikanan tuna Indonesia, serta di PPS Nizam Zachman.

2. Regulasi/kebijakan pemerintah terkait industri tuna dan penanganan tuna

Permen No 27 tahun 2012 merupakan regulasi pemerintah terkait dengan pedoman umum industrialisasi perikanan dan kelautan. Pemerintah mendukung industrialisasi perikanan dan kelautan melalui peningkatan nilai tambah dan daya saing produk, modernisasi sistem produksi hulu dan hilir, penguatan pelaku industri kelautan dan perikanan, dan lain-lain. Setiap stakeholder tuna yang akan mengirimkan produk tuna segar dan olahan juga harus memiliki sertifikat dan standar-standar seperti standar SNI yang telah ditetapkan oleh pemerintah Indonesia dan negara penerima.

KEPMEN 01/MEN/2007 tentang

Persyaratan Jaminan Mutu dan Keamanan Hasil Perikanan pada Proses Produksi, Pengolahan, dan Distribusi menyatakan bahwa kegiatan bongkar muat dan pendaratan dilakukan dengan cepat; menempatkan produk perikanan dan tidak terlambat dalam melakukan perlindungan suhu; serta tidak menggunakan peralatan dan perlakuan yang menyebabkan hal-hal kerusakan yang tidak diinginkan pada bagian produk perikanan. Penerapan sistem manajemen mutu HACCP di UPI dan traceability kapal perikanan sudah selayaknya dilakukan untuk dapat menjamin mutu produk ekspor tuna Indonesia (Nurani et al. 2011).

3. Aksesibilitas dari PPS Nizam Zachman ke sarana transportasi (pelabuhan dan bandara) relatif mudah dan cepat

Akses dari dan menuju ke industri tuna yang ada di PPS Nizam Zachman sangat mudah dan strategis. Akses jalan raya di area PPS Nizam Zachman cukup lebar, sehingga dapat diakses oleh setiap pengguna. Akses untuk memasarkan produk perikanan tuna di PPS Nizam Zachman sangat mudah, karena PPS Nizam Zachman berjarak $25 \mathrm{~km}$ ke Bandara Soekarno Hatta dan berjarak 12 km ke Pelabuhan Internasional, sehingga 
jarak tempuh ke bandara ataupun ke pelabuhan niaga untuk ekspor produk olahan tuna ataupun produk tuna segar ke Jepang, Amerika, serta Eropa dapat ditempuh dalam waktu yang tidak terlalu lama.

\section{Ancaman (threats)}

1. Penolakan produk perikanan tuna dari luar negeri

Penolakan produk perikanan tuna dari luar negeri biasanya terkait dengan kurangnya ketelitian selama proses produksi, misalnya terdapatnya noda pada produk olahan, terdapat rambut pada produk olahan, hingga kadar histamin yang meningkat pada produk tuna yang salah satu disebabkan oleh pengaturan suhu ruangan selama proses pengiriman yang tidak sesuai. Hal tersebut menyebabkan negara penerima mengembalikan tuna segar dan tuna olahan ke negara pengirim tuna. Kasus penolakan produk perikanan Indonesia terdapat pada Tabel 3.

Penyebab utama dari penolakan produk perikanan Indonesia adalah adanyakontaminasi bakteri. Kontaminasi bakteri ini disebabkan lemahnya proses pengawasan selama proses produksi produk-produk perikanan Indonesia serta penanganan yang kurang tepat sejak di atas kapal hingga ikan dibawa ke coldstorage. Peran pelabuhan perikanan dalam bidang penanganan dan pengawasan produk perikanan sangat diperlukan untuk meminimalisir penolakan ekspor hasil perikanan.
2. Persaingan harga tuna segar dan olahan dari negara lain (kompetitor)

Harga ikan tuna di negara-negara tujuan ekspor akan memengaruhi besarnya nilai ekspor ikan tuna. Harga di pasar luar negeri akan berkaitan dengan mutu produk yang diekspor dan juga dipengaruhi oleh kemampuan suatu negara mengatasi hambatan-hambatan di pasar tujuan ekspor. Semakin tinggi mutu ikan tuna olahan yang dijual, maka semakin tinggi harganya (Lestari et al. 2013).

Persaingan harga tuna segar dan tuna olahan dari negara lain atau kompetitor merupakan suatu ancaman bagi industri tuna Indonesia, untuk itu diperlukan penanganan yang baik mulai dari kegiatan penangkapan, pendaratan hingga penanganan di industri tuna. Bila penanganan yang baik telah diterapkan oleh seluruh pelaku perikanan tuna, maka diharapkan tuna segar dan tuna olahan Indonesia dapat bersaing dengan negara lain.

3. Standar mutu yang tinggi dari negara lain

Setiap negara menerapkan standar yang berlaku di negaranya masing-masing sebagai acuan dalam impor dan ekspor hasil perikanan, hal ini mengakibatkan banyaknya standar yang harus dipenuhi oleh industri pengekspor tuna dan standar tersebut harus dipatuhi oleh industri tuna Indonesia, agar produk tuna Indonesia dapat diterima dan dikonsumsi oleh negara penerima.

Tabel 3. Kasus penolakan ekspor hasil perikanan oleh negara mitra tahun 2011-2018

\begin{tabular}{llcccccccc}
\hline \multirow{2}{*}{ No } & \multirow{2}{*}{ Negara Mitra } & \multicolumn{7}{c}{ Kasus Penolakan } \\
\cline { 2 - 9 } & $\mathbf{2 0 1 1}$ & $\mathbf{2 0 1 2}$ & $\mathbf{2 0 1 3}$ & $\mathbf{2 0 1 4}$ & $\mathbf{2 0 1 5}$ & $\mathbf{2 0 1 6}$ & $\mathbf{2 0 1 7}$ & $\mathbf{2 0 1 8}$ \\
\hline 1 & Cina & 2 & 0 & 0 & 0 & 0 & 2 & 0 & 1 \\
2 & Kanada & 0 & 0 & 5 & 4 & 1 & 2 & 3 & 5 \\
3 & Vietnam & 0 & 0 & 0 & 0 & 0 & 4 & 0 & 0 \\
4 & Rusia & 6 & 1 & 4 & 0 & 2 & 3 & 1 & 0 \\
5 & Korea Selatan & 1 & 2 & 3 & 2 & 1 & 0 & 1 & 0 \\
6 & Norwegia & 0 & 0 & 0 & 0 & 0 & 0 & 0 & 0 \\
7 & Italia & 3 & 9 & 1 & 1 & 1 & 1 & 1 & 5 \\
8 & Spanyol & 2 & 3 & 0 & 1 & 0 & 1 & 2 & 3 \\
9 & Perancis & 2 & 1 & 1 & 1 & 2 & 2 & 3 & 1 \\
10 & Inggris & 0 & 1 & 0 & 1 & 2 & 0 & 2 & 0 \\
\hline
\end{tabular}

Sumber: Kementerian Kelautan Perikanan (2018) 
Menurut Lestari et al. (2013) negara-negara tujuan ekspor ikan tuna mempunyai persyaratan impor yang berbeda-beda antara satu dengan lainnya. Oleh karena itu, dalam memproduksi produk perlu direncanakan terlebih dahulu produk dimaksud akan menembus pasar negara mana, sehingga saat memproduksi produk perlu diusahakan produk yang memenuhi persyaratan di negara yang akan di tuju. Upaya yang dilakukan agar produk olahan Indonesia dapat bersaing dengan pasar internasional adalah peningkatan mutu produk olahan. Karena mutu produk olahan tuna akan sangat menentukan penguasaan pasar internasional. Peningkatan mutu perlu dilakukan dari sisi hulu sampai dengan hilir. Penanganan ikan tuna pada saat penangkapan, pasca penangkapan, distribusi/selama transportasi dari pelabuhan ke tempat pengolahan sampai dengan penerapan GMP dan HACCP perlu dilakukan dengan baik.

\section{Strategi Pengembangan PPS Nizam Zachman}

Penentukan strategi pengembangan PPS Nizam Zachman dalam mendukung industri perikanan tuna sesuai dengan faktor internal dan eksternl dari pengelola PPS Nizam Zachman maka dilakukan analisis melalui matriks SWOT (Tabel 4), dimana analisis yang dihasilkan merupakan gabungan antara kondisi internal dan eksternal.

Setelah didapat strategi pengembangan PPS Nizam Zachman dalam mendukung industri tuna, kemudian dilakukan rangking terhadap keenam strategi pengembangan pelabuhan. Urutan prioritas strategi pengembangan PPS Nizam Zachman terdapat pada Tabel 5.

Analisis SWOT pengembangan industri tuna di PPS Nizam Zachman menghasilkan enam kombinasi strategi. Strategi yang dipilih berdasarkan hasil penggabungan antara faktor internal dan faktor eksternal dari pengembangan industri tuna berdaya saing.

Strategi S-O yang dipilih yaitu :

SO1 : Peningkatan kualitas dan jumlah produksi tuna

Peningkatan kualitas dan jumlah produksi tuna olahan dan tuna segar merupakan salah satu strategi kombinasi kekuatan dan peluang, yang dapat menjadi salah satu strategi pengembangan PPS Nizam Zachman dalam mendukung industri perikanan tuna. Peningkatan kualitas dan jumlah produksi dapat dilakukan dengan menerapkan sistem manajemen mutu HACCP di unit pengolahan ikan dan traceability di kapal perikanan. Perikanan tuna merupakan perikanan skala industri dengan tujuan utama hasil tangkapannya untuk skala ekspor (Nurani et al. 2011). Peningkatan kualitas dan jumlah produksi tuna dilakukan dengan penerapan mutu HACCP dan memenuhi persyaratan mutu tujuan negara ekspor.

SO2 : Memanfaatkan dan meningkatkan pelayanan pengiriman produk tuna dengan sarana transportasi yang tersedia

Memanfaatkan dan meningkatkan pelayanan pengiriman produk tuna segar maupun olahan dengan menggunakan sarana transportasi pemasaran yang tersedia, yaitu mobil berpendingin, kapal kargo, dan pesawat terbang dengan maksimal. Langkah strategi kombinasi kekuatan dan peluang ini dapat dilakukan dengan menambah jumlah kendaraan berpendingin yang disediakan di PPS Nizam Zachman, agar pengusaha tuna mau memanfaatkan kendaraan yang disediakan oleh pelabuhan. Menyediakan fasilitas dermaga kapal kargo untuk pengiriman produk olahan tuna

SO3 : Meningkatkan ketaatan SDM dalam menerapkan regulasi mengenai industri tuna

SDM di PPS Nizam Zachman yang mampu melakukan kegiatan penanganan tuna sudah sangat baik, namun ketaatan dalam menerapkan regulasi dalam kegiatan penanganan tuna masih harus terus diterapkan agar didapatkan produk perikanan dengan kualitas yang baik dan harga jual yang tinggi. Produk tuna ekspor dapat diterima dengan baik oleh konsumen di luar negeri.

Strategi S-T yang dipilih yaitu :

ST1 : Meningkatkan sosialisasi regulasi ekspor tuna

Peningkatan ekspor tuna merupakan salah satu strategi kombinasi kekuatan dan ancaman. Strategi pengembangan pelabuhan ini digunakan untuk meningkatkan kesadaran pengelola pelabuhan dan stakeholder dalam kegiatan ekspor produk perikanan, yaitu dengan meningkatkan sosialisasi mengenai regulasi terkait dengan ekspor tuna. 
Tabel 4. Matriks SWOT strategi pengembangan PPS Nizam Zachman dalam mendukung industri perikanan tuna

\begin{tabular}{|c|c|c|}
\hline Faktor Internal & $\begin{array}{l}\text { Kekuatan (strengths) } \\
\text { 1. Tingginya harga jual tuna } \\
\text { yang didaratkan di PPS } \\
\text { Nizam Zachman (S1) } \\
\text { 2. Tersedianya SDM yang } \\
\text { mampu menjalankan } \\
\text { kegiatan di PPS Nizam } \\
\text { Zachman berkaitan } \\
\text { dengan penanganan tuna } \\
\text { (S2) } \\
\text { 3. Ketersediaan sarana } \\
\text { prasarana pendukung } \\
\text { industri perikanan } \\
\text { tuna (air bersih, es, } \\
\text { coldstorage) (S3) } \\
\text { Baiknya kualitas ikan } \\
\text { tuna yang didaratkan di } \\
\text { PPS Nizam Zachman (S4) } \\
\text { Baiknya pendataan hasil } \\
\text { tangkapan ikan yang } \\
\text { didaratkan di PPS Nizam } \\
\text { Zachman (S5) }\end{array}$ & $\begin{array}{l}\text { Kelemahan (weaknesses) } \\
\text { 1. Keterbatasan dalam } \\
\text { pemenuhan bahan baku } \\
\text { tuna (W1) } \\
\text { 2. } \begin{array}{l}\text { Penanganan tuna masih } \\
\text { kurang higienis saat } \\
\text { didaratkan (W2) }\end{array} \\
\text { 3. Minimnya ketersediaan } \\
\text { fasilitas pemasaran (ke } \\
\text { industri, pasar) (W3) } \\
\text { 4. Minimnya pelayanan } \\
\text { informasi harga dan } \\
\text { pasar (W4) } \\
\text { 5inimnya ketersediaan } \\
\text { fasilitas fungsional (W5) }\end{array}$ \\
\hline Faktor Eksternal & & \\
\hline 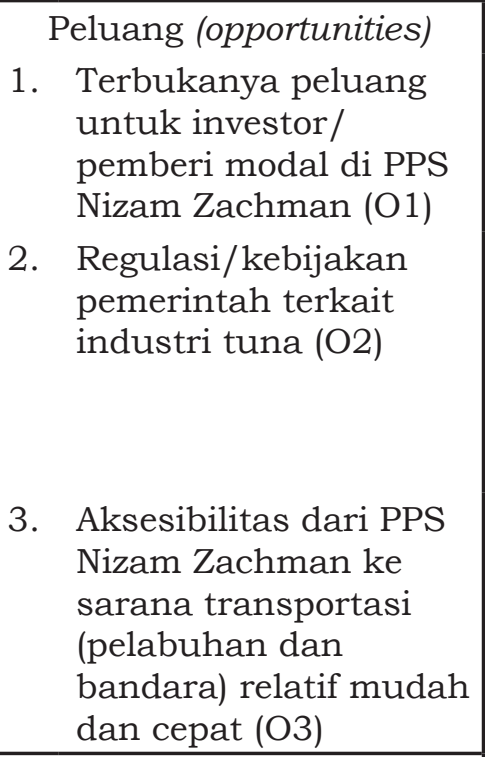 & \begin{tabular}{ll}
\multicolumn{1}{c}{ Strategi S-O } \\
1. & $\begin{array}{l}\text { Peningkatan kualitas dan } \\
\text { jumlah produksi ekspor } \\
\text { tuna (S1S4O1O2) }\end{array}$ \\
2. & $\begin{array}{l}\text { Pemanfaatan dan } \\
\text { meningkatkan pelayanan } \\
\text { pengiriman produk } \\
\text { tuna dengan sarana } \\
\text { transportasi yang tersedia } \\
\text { (S2S3O3) }\end{array}$ \\
3. & $\begin{array}{l}\text { Peningkatan ketaatan } \\
\text { SDM dalam menerapkan } \\
\text { regulasi mengenai } \\
\text { industri tuna(S3S4O3) }\end{array}$
\end{tabular} & \begin{tabular}{l}
\multicolumn{1}{c}{ Strategi $\mathrm{W}-\mathrm{O}$} \\
1. \\
Penyediaan fasilitas \\
pemasaran yang higienis \\
sesuai dengan regulasi \\
(W2W3O2)
\end{tabular} \\
\hline 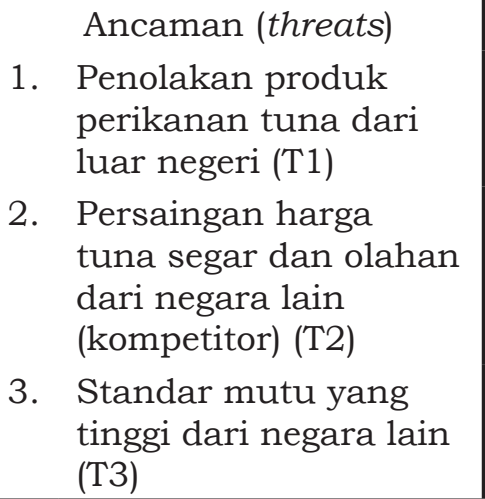 & \begin{tabular}{l}
\multicolumn{1}{c}{ Strategi S-T } \\
1. \\
Peningkatan sosialisasi \\
regulasi ekspor tuna \\
(S3S4T1T3)
\end{tabular} & \begin{tabular}{l}
\multicolumn{1}{c}{ Strategi W-T } \\
1. Peningkatan \\
pengawasan dalam \\
penanganan tuna agar \\
harga jual tuna dapat \\
bersaing(W2W5T2)
\end{tabular} \\
\hline
\end{tabular}


Tabel 5. Prioritas strategi pengembangan PPS Nizam Zachman dalam mendukung industri tuna

\begin{tabular}{|c|c|c|c|c|c|}
\hline \multirow{2}{*}{ Prioritas strategi } & \multicolumn{3}{|c|}{$\begin{array}{c}\text { Kriteria/Parameter yang } \\
\text { dipertimbangkan }\end{array}$} & \multirow{2}{*}{ Total } & \multirow{2}{*}{ Ranking } \\
\hline & $\begin{array}{c}\text { Urgency/ } \\
\text { Kemendesakan }\end{array}$ & Seriousness & Growth & & \\
\hline $\begin{array}{l}\text { Peningkatan kualitas dan } \\
\text { jumlah produksi ekspor } \\
\text { tuna (S-O1) }\end{array}$ & 5 & 4 & 5 & 14 & I \\
\hline $\begin{array}{l}\text { Pemanfaatan dan mening- } \\
\text { katkan pelayanan pengiri- } \\
\text { man produk tuna dengan } \\
\text { sarana transportasi yang } \\
\text { tersedia (S-O2) }\end{array}$ & 4 & 3 & 4 & 11 & III \\
\hline $\begin{array}{l}\text { Peningkatan ketaatan SDM } \\
\text { dalam menerapkan regulasi } \\
\text { mengenai industri tuna (S- } \\
\text { O3) }\end{array}$ & 3 & 3 & 4 & 10 & IV \\
\hline $\begin{array}{l}\text { Penyediaan fasilitas pema- } \\
\text { saran yang higienis sesuai } \\
\text { dengan regulasi (W-O) }\end{array}$ & 4 & 4 & 4 & 12 & II \\
\hline $\begin{array}{l}\text { Peningkatan sosialisasi } \\
\text { regulasi ekspor tuna (S-T) }\end{array}$ & 5 & 3 & 4 & 12 & II \\
\hline $\begin{array}{l}\text { Peningkatan pengawasan } \\
\text { dalam penanganan tuna } \\
\text { agar harga jual tuna dapat } \\
\text { bersaing (W-T) }\end{array}$ & 4 & 3 & 4 & 11 & III \\
\hline
\end{tabular}

Strategi W-O yang dipilih yaitu :

WO1 : Menyediakan fasilitas pemasaran yang higienis sesuai dengan regulasi jaminan mutu

Menyediakan fasilitas pemasaran yang higienis merupakan salah satu bentuk upaya meningkatkan pelayanan dalam mendukung kegiatan industri. Tahapan yang dilakukan adalah dimulai dari peningkatan pelayanan penyediaan fasilitas pemasaran yang higienis sesuai dengan aktivitas bongkar muat hasil tangkapan tuna di PPS Nizam Zachman. Strategi kombinasi kelemahan dan peluang ini dapat dijadikan salah satu alternatif pengembangan pelabuhan perikanan.

Strategi W-T yang dipilih yaitu :

WT1 : Peningkatan pengawasan dalam penanganan tuna agar harga jual tuna dapat bersaing

Pengawasan terhadap penanganan tuna saat didaratkan dari atas kapal ke darat. Dengan memperhatikan alat bantu yang digunakan, kebersihan alat bantu yang digunakan, metode atau air bersih yang digunakan untuk dalam membersihkan. PPS Nizam Zachman dapat melakukan tinjauan langsung ke lapangan mengenai penanganan tuna yang selama ini dilakukan di PPS Nizam Zachman dan melakukan sosialisasi mengenai penanganan tuna yang baik saat didaratkan dan dibawa ke area industri bila terjadi penanganan yang tidak sesuai dengan ketentuan yang berlaku. Menurut Nurani et al. (2013) tahapan-tahapan penanganan ikan di PPS Nizam Zachman adalah pembongkaran ikan di pelabuhan, pemindahan ikan ke transit sheed, sortasi kualitas ikan, pembersihan sisa isi perut dan bagian insang, penimbangan dan pencatatan, penyimpanan, pengemasan dan tahapan yang terakhir yaitu pengujian laboratorium.

Hasil penentuan prioritas strategi pengembangan PPS Nizam Zachman, didapatkan urutan sebagai berikut:

1. Prioritas utama dalam strategi pengembangan PPS Nizam Zachman adalah peningkatan kualitas dan jumlah produksi ekspor tuna (S-O1)

2. Urutan kedua adalah menyediakan fasilitas pemasaran yang higienis (WO) dan peningkatan sosialisasi regulasi ekspor tuna (S-T)

3. Pemanfaatan dan meningkatkan 
pelayanan pengiriman produk tuna dengan sarana transportasi yang tersedia (S-O2) dan Peningkatan pengawasan dalam penanganan tuna agar harga jual tuna dapat bersaing (W-T)

4. Peningkatan ketaatan SDM dalam menerapkan regulasi mengenai industri tuna (S-O3)

Urutan prioritas strategi pengembangan PPS Nizam Zachman ini merupakan hasil analisis lanjutan yang dilakukan oleh peneliti. Strategi yang dirumuskan berdasarkan kondisi yang terjadi di PPS Nizam Zachman dengan memperhatikan kekuatan, kelemahan, peluang, dan ancaman. Strategi yang menjadi prioritas utama dalam pengembangan PPS Nizam Zachman dalam mendukung industri perikanan tuna adalah dalam meningkatkan kualitas dan jumlah produksi ekspor tuna. Pentingnya meningkatkan kualitas dan jumlah produksi ekspor tuna mengingat PPS Nizam Zachman tercatat melakukan ekspor produk perikanan ke 54 (lima puluh empat) negara tujuan (Sam et al. 2011). Keenam strategi ini dapat menjadi bahan pertimbangan bagi pihak pengelola pelabuhan.

\section{KESIMPULAN DAN SARAN}

\section{Kesimpulan}

Kesimpulan yang didapat dari penelitian ini adalah terdapat enam strategi yang dapat digunakan sebagai pengembangan industri tuna berdaya saing. Keenam strategi tersebut adalah:

1. Peningkatan kualitas dan jumlah produksi tuna olahan dan tuna segar;

2. Menyediakan fasilitas pemasaran yang higienis sesuai dengan regulasi;

3. Meningkatkan sosialisasi regulasi ekspor tuna;

4. Memanfaatkan dan meningkatkan pelayanan pengiriman produk tuna dengan sarana transportasi yang tersedia; dan

5. Peningkatan pengawasan dalam penanganan tuna

\section{Saran}

Pentingnya penyediaan fasilitas pokok, penunjang, dan fungsional yang tidak hanya untuk industri tuna, tetapi seluruh industri perikanan yang ada di kawasan PPS Nizam Zachman, serta mengoptimalkan fasilitas penunjang industri perikanan tuna yang telah disediakan PPS Nizam Zachman, seperti tempat khusus pelelangan ikan tuna dan dermaga bongkar muat ikan tuna. Hal tesebut bertujuan agar seluruh stakeholder menjadi semakin puas dengan kinerja dari PPS Nizam Zachman.

\section{DAFTAR PUSTAKA}

[DJPT] Direktorat Jenderal Perikanan Tangkap. 2015. Profil Pelabuhan Perikanan Samudera Nizam Zachman Jakarta. Jakarta (ID): Kementerian Kelautan dan Perikanan.

Harefa JSPJ, Solihin I, Wisudo SH. 2019. Analisis Kebutuhan Industri Perikanan Purse Seine terhadap Kelembagaan di Pelabuhan Perikanan Samudera Nizam Zachman [Skripsi]. Bogor: Fakultas Perikanan dan Ilmu Kelautan, Institut Pertanian Bogor.

Hutapea RYF, Solihin I, Nurani TW. 2017. Peran Pelabuhan Perikanan Samudera Nizam Zachman dalam Mendukung Industri Tuna. Marine Fisheries. 8: 187-198.

Lestari W, Syarief R, Sumantadinata K. 2013. Strategi Peningkatan Daya Saing Olahan Tuna di Pasar Internasional. Jurnal Manajemen IKM. 8: 36-44.

Lubis E, Pane AB. 2012. An Model Optimum of Fish Auction in Indonesian Fishing Ports in Accordance with the Characteristics of Fisherman. Journal of Costal Development. 15: 282-296.

Menteri Kelautan dan Perikanan Republik Indonesia. 2007. Peraturan Menteri Kelautan dan Perikanan Republik Indonesia. Nomor PER.01/ MEN/2007 tentang Persyaratan Jaminan Mutu dan Keamanan Hasil Perikanan pada Proses Produksi, Pengolahan dan Distribusi. Jakarta.

Menteri Kelautan dan Perikanan Republik Indonesia. 2012. Peraturan Menteri Kelautan dan Perikanan Republik Indonesia. Nomor PER.08/ MEN/2012 tentang Kepelabuhanan Perikanan. Jakarta.

Menteri Kelautan dan Perikanan Republik Indonesia. 2012. Peraturan Menteri Kelautan dan Perikanan Republik Indonesia. Nomor PER.27/ MEN/2012 tentang Pedoman Umum Industrialisasi Kelautan dan Perikanan. Jakarta. 
Menteri Kelautan dan Perikanan Republik Indonesia. 2018. Kementerian Kelautan dan Perikanan dalam Angka Tahun 2018. Pusat Data Statistik dan Informasi Kementerian Kelautan dan Perikanan. Jakarta.

Nurani TW, Iskandar BH, Wahyudi GA. 2011. Kelayakan Dasar Penerapan HACCP di Kapal Fresh Tuna Longline. Jurnal Pengolahan Hasil Perikanan Inonesia. 14: 115-123.

Nurani TW, Murdaniel RPS, Harahap MH. 2013. Upaya Penanganan Mutu Ikan Tuna Segar Hasil Tangkapan Kapal Tuna Longline untuk Tujuan Ekpor. Marine Fisheries. 4: 153-162.

Rangkuti F. 2006. Measuring Customer Satisfaction. Jakarta. Indonesia. PT Gramedia Pustaka Utama.

Sam AR, Wisudo SH, Murdiyanto B, Iskandar BH. 2011. Strategi Pengembangan Pelabuhan Perikanan Samudera Nizam Zahman Jakarta sebagai Pusat Pemasaran Perikanan. Marine Fisheries. 2: 129-139.

Utari E, Wahyuni I. 2020. Analisis Matriks USG (Urgency, Seriousness, and Growth) Banten Mangrove Center bagi Masyarakat Kelurahan Sawah Luhur Kecamatan Kasemen Kota Serang. Jurnal Biologi dan Pembelajarannya. 15: 31-42. 